\title{
ANALISIS BAURAN PROMOSI PADA PT.ANUGRAH PARAHYANGAN JAYA
}

\author{
Yayan Sofyan \\ Sekolah Tinggi Ilmu Ekonomi Muhammadiyah Bandung \\ yayansoftyan1971@yahoo.co.id
}

\begin{abstract}
ABSTRAK
Pemasaran merupakan kekuatan utama dalam bisnis dan masyarakat yang bermula dan berakhir dari kebutuhan konsumen. Konsep dari pemasaran adalah sistem keseluruhan dari kegiatan usaha untuk merencanakan, menetukan harga, mempromosikan dan mendistribusikan barang atau jasa yang dapat memuaskan kebutuhan konsumen, Analisis terhadap hasil implementasi dari strategi Bauran Promosi penting untuk dilakukan guna melihat sejauhmana pengaruh dari strategi bauran promosi tersebut dalam mendongkrak nilai penjualan perusahaan. Hasil analisis ini akan berguna sebagai pedoman bagi pihak manajemen perusahaan, khususnya perusahaan pengembang pasar Ciroyom untuk mengambil langkah-langkah kebijakan yang sesuai dan tepat sasaran.

Analisis data proses mengorganisasikan dan mengurutkan data ke dalam pola,kategori dan satuan uraian dasar sehingga dapat ditemukan tema dan dapat dirumuskan hipotesis kerja seperti yang didasarkan oleh data, dalam menganalisis data penulis menggunakan metode perhitungan rata-rata (mean), modus, dan median

Pelaksanaan Bauran Promosi di PT.Anugrah Parahyangan Plaza adalah Iklan di radio,pemasangan Billboard di tempat-tempat yang strategis, Brosur-brosur yang disebarkan ditempat-tempat keramaian dengan iklan ini diharapkan konsumen lebih mengenal PT.Anugrah Parahyangan Jaya sehingga perusahaan dapat menuai hasil dari tujuan diadakannya iklan yaitu meningkatkan permintaan awal ,mengembangkan pada pilihan pada perusahaan dan yang terakhir untuk meyakinkan pembeli tentang produk yang ditawarkan oleh PT.Anugrah Parahyangan Jaya bisa dinikmati oleh konsumen

Promosi penjualan yang dilakukan di PT.Anugrah Parahyangan Jaya menggunakan potongan harga berupa discount time apabila konsumen membeli kios atau toko pada waktu tertentu dan ini terbukti efektif untuk merangsang penjualan dalam waktu yang pendek dan dalam jangka panjang perusahaan dapat menarik pelanggan baru,Penjualan personal pada PT.Anugrah Parahyangan Jaya dengan cara komunikasi langsung antara SPG dengan konsumen, biasanya PT.Anugrah Parahyangan Jaya mengikuti pameran dagang property yang diselenggarakan oleh Event Orgazer sehingga terjadi kontak langsung antara SPG PT.Anugrah Parahyangan Jaya dengan konsumen dan ini biasanya langsung terjadi transaksi apabila konsumen cocok dengan penawaran yang ditawarkan oleh pihak perusahaan
\end{abstract}

Kata Kunci : Bauran Promosi dan Pemasaran 


\section{ABSTRACT}

Marketing is a major force in business and society that began and ended the needs of consumers. The concept of marketing is a whole system of business activities to plan, determine pricing, promoting and distributing goods or services that can satisfy consumer needs, analysis of the results of the implementation of the strategy is important for the Promotion Mix done to see how far the influence of these promotion strategies in increasing the value company's sales. The results of this analysis will be useful as guidelines for the management of companies, especially companies Ciroyom market developers to take steps appropriate policies and targeted.

The data analysis process to organize and sort the data into patterns, categories and units so that the basic outline can be found in the theme and can be formulated as a working hypothesis based on the data, the authors analyzed the data using the method of calculating the average (mean), mode, and median Implementation of the Promotion Mix PT.Anugrah Parahyangan Plaza is on the radio ads, billboard installation in strategic places, distributed brochures places crowded with ads consumers are expected to know more about PT.Anugrah Parahyangan Jaya so that companies can reap the results of purpose of the advertising that is increasing demand for early, developing the options on the company and the last to convince buyers of the products offered by PT.Anugrah Parahyangan Jaya can be enjoyed by consumers

Sales promotions conducted in PT.Anugrah Parahyangan Jaya using time rebate form discount if consumers buy a kiosk or shop at a specific time and is proven effective to stimulate sales in a short time and in the long term the company can attract new customers, sales personnel in PT . Anugrah Jaya Parahyangan by direct communication between the SPG to the consumer, usually PT.Anugrah Parahyangan Jaya following property trade show organized by Event Orgazer resulting in direct contacts between the SPG PT.Anugrah Parahyangan Jaya with consumers and this usually occurs when the consumer transaction fits with the bid offered by the company

Keywords: Promotion Mix and Marketing

\begin{abstract}
Pendahuluan
Dalam menghadapi era perdagangan bebas kini setiap perusahaan mengubah format strategi promosi salah satunya berorientasi pada bagaimana membangun perusahaan yang kuat. Oleh karena itu, perusahaan harus mengembangkan strategi promosinya agar tetap bertahan ditengah-tengah gelombang persaingan untuk memasuki pasar yang cukup tinggi. Dan satu yang tidak boleh dilupakan oleh perusahaan adalah konsumen,
\end{abstract}

perlu disadari bahwa perubahan gaya hidup saat ini menyebabkan konsumen juga mempunyai cara sendiri dalam memenuhi kebutuhan konsumen.(Jurnal Manajemen Pemasaran Edisi September : 2009) Setiap perusahaan dalam memasarkan produknya tertentu menerapkan berbagai macam strategi promosi. Kegiatan promosi pada intinya memfokuskan diri pada Perikalan (adveritsing), penjualan (Sales promotion ), (Publicity) dalam 
hubungan masyarakat dan penjualan pribadi (personal selling) yang dalam hal ini dikenal sebagai Bauran Promosi. Kegiatan promosi tentunya membutuhkan suatu strategi. Strategi ini tentu harus mampu memberikan kontribusi terhadap pencapaian tujuan perusahaan yaitu peningkatan penjualan. .(Jurnal Manajemen Pemasaran Edisi September : 2009)

Bauran Promosi (Promotion mix) didalam suatu organisasi merupakan suatu ramalan khusus yang terdiri dari iklan, penjualan pribadi, promosi penjualan dan hubungan masyarakat yang dipergunakan perusahaan untuk mencapai tujuan iklan dan promosinya, Bauran Promosi merupakan suatu strategi promosi untuk setiap perusahaan dapat mencapai pangsa pasar yang diinginkan, dengan biaya lebih tinggi tetapi berharap memperoleh pangsa pasar dan penghasilan lebih besar.

Agar promosi dapat diterima konsumen maka dilakukan suatu kegiatan promosi dan distrubusi yang dapat membuat konsumen tertarik hingga

berkeinginan untuk membeli produk, untuk itu diperlukan kegiatan promosi dan

distribusi yang terorganisir dengan baik dan berkesinambungan sehingga bermanfaat dan dapat diterima dengan jelas oleh konsumen.

Promosi merupakan suatu usaha untuk meningkatkan penjualan dengan memberi informasi mengenai produk yang tersedia dan berkomunikasi dengan pelanggan agar dapat menyampaikan pesan produsen tentang produk ditawarkan guna meningkatkan penjualan pada setiap perusahaan. Selain promosi, pihak perusahaan juga harus memperhitungkan tentang kemudahan memperoleh produk agar produk yang disalurkannya dapat tepat waktu pada saat dibutuhkan. Sebagaimana yang telah diuraikan di atas bahwa untuk mencapai tujuan perusahaan maka diperlukan sebuah strategi, dalam hal ini adalah strategi bauran

promosi. Strategi bauran promosi adalah sebuah stategi tentang kebijakan

iklan (Advertising, Promosi Penjualan (Sales Promotion), Hubungan Masyarakat (PublicRelation) dan Penjualan Personal (Personal Selling) Kotler

(2002:376)

Keberhasilan suatu perusahan dalam persaingan bisnis yang semakin ketat dapat di tinjau dari penerapan strategi Bauran Promosinya. Demikian pula halnya dengan PT.Anugrah Parahyangan Jaya sebagai developer Pembangunan Pasar dan Sub Terminal yang berlokasi di Jln.Surya Sumantri Ruko 5A Bandung tentunya memerlukan strategi Bauran Promosi yang tepat guna meningkatkan penjualan produknya, yaitu dengan memperhatikan aspek iklan (Advertising), Promosi Penjualan (Sales Promotion), Hubungan Masyarakat (PublicRelation) dan Penjualan Personal (Personal Selling).

Berikut data target penjualan dan realisasi penjualan toko dan kios di pasar ciroyom Bandung 
Tabel 1

Target dan Realisasi Penjualan Toko dan Kios di Pasar Ciroyom

\begin{tabular}{|c|c|c|c|}
\hline Tahun & Target & $\begin{array}{c}\text { Actual } \\
\mathbf{y}\end{array}$ & Cost (RP) \\
\hline $\mathbf{2 0 1 3}$ & 40 & 36 & 40.000 .000 \\
\hline $\mathbf{2 0 1 4}$ & 80 & 69 & 60.000 .000 \\
\hline $\mathbf{2 0 1 5}$ & 85 & 70 & 60.000 .000 \\
\hline $\mathbf{2 0 1 6}$ & 100 & 106 & 90.000 .000 \\
\hline $\mathbf{2 0 1 7}$ & 125 & 120 & 110.000 .000 \\
\hline
\end{tabular}

Sumber:PT.Anugrah Parahyangan

Dari tabel 1 diatas terlihat ada ketidasesuaian antara target yang di tetapkan oleh perusahaan dan realisasinya, oleh karena itu penulis mencoba untuk memecahkan masalah yang ada diperusahaan dengan melihat strategi promosi yang dijalankan oleh perusahaan

Analisis terhadap hasil implementasi dari strategi Bauran Promosi penting untuk dilakukan guna melihat sejauhmana pengaruh dari strategi bauran promosi tersebut dalam mendongkrak nilai penjualan perusahaan. Hasil analisis ini akan berguna sebagai pedoman bagi pihak manajemen perusahaan, khususnya perusahaan pengembang pasar Ciroyom untuk mengambil langkahlangkah kebijakan yang sesuai dan tepat sasaran.

Berdasarkan uraian latar belakang permasalahan di atas penulis tertarik untuk mengambil judul tugas ini yaitu : "ANALISIS BAURAN PROMOSI PADA PT.ANUGRAH PARAHYANGAN JAYA

\section{Identifikasi Masalah}

Berdasarkan uraian diatas maka penulis mengindentifikasikan masalah sebagai berikut : a. Bagaimana Pelaksanaan Bauran Promosi dalam Mamasarkan Produk Kios dan Toko Pasar Ciroyom di PT.Anugrah Parahyangan Jaya

b. Faktor-faktor apa saja yang menjadi kendala dalam Pelaksanaan Bauran Promosi dalam Mamasarkan Produk Kios dan Toko Pasar Ciroyom di PT.Anugrah Parahyangan Jaya

c. Bagaimana Pemecahan Masalah Pelaksanaan Bauran Promosi dalam Mamasarkan Produk Kios dan Toko Pasar Ciroyom di PT.Anugrah Parahyangan Jaya

\section{Maksud dan Tujuan Penelitian}

Maksud dari penelitian ini adalah untuk membuktikan apakah pelaksanaan bauran promosi yang dilaksanakan di PT.Anugrah Parahyangan Jaya dapat meningkatkan penjualan sehingga hasil penelitian diharapkan dapat menjadi informasi yang berguna baik bagi perusahaan maupun bagi ilmu pengetahuan.

\section{Sedangkan Tujuan dari} Penelitian ini adalah :

1. Untuk mengetahui pelaksanaan Bauran Promosi dalam Mamasarkan Produk Kios dan Toko Pasar Ciroyom di PT.Anugrah Parahyangan Jaya

2. Untuk mengetahui Faktor-faktor apa saja yang menjadi kendala dalam PelaksanaanBauran Promosi dalam Mamasarkan Produk Kios dan Toko Pasar 
Ciroyom di PT.Anugrah Parahyangan Jaya

3. Untuk mengetahui Pemecahan Masalah Pelaksanaan Bauran Promosi dalam Mamasarkan Produk Kios dan Toko Pasar Ciroyom di PT.Anugrah Parahyangan Jaya

\section{Kerangka Pemikiran}

Kerangka pikir dan penelitian perlu dikemukakan apabila pada penelitian tersebut berkenaan dengan dua variabel atau lebih. Uma Sakaran dalam Sugiyono (2008:47) berpendapat bahwa kerangka berpikir merupakan model konseptual tentang bagaimana teori berhubungan dengan berbagai faktor yang telah diidentifikasi sebagai masalah yang penting, dimana selanjutnya sintesa tentang hubungan variabel-variabel tersebut digunakan untuk merumuskan hipotesis.

Pada penelitian ini, bauran promosi yang meliputi advertising, personal selling, sales promotion merupakan variabel promosi yang digunakan perusahaan untuk menarik para calon konsumennya. Setiap perusahaan tentunya mempunyai tujuan masing-masing,secara umum tujuan perusahaan adalah untuk mendapatkan laba atau keuntungan yang maksimal untuk itu perusahaan harus menentukan strategi-strategi apa yang harus dilakukan oleh perusahaan untuk mencapai tujuannya itu

Salah satu strategi yang biasanya dilakukan oleh perusahaan untuk mencapai tujuannya itu adalah dengan meningkatkan strategi bauran promosi yang dimiliki oleh perusahaannya yang terdiri dari Periklanan, Promosi
Penjualan,Hubungan

Masyarakat,Penjualan Personal dan Pemasaran Langsung Kotler (2002 : 642)

Kunci keberhasilan dalam menerapkan bauran pemasaran yang baik bagi perusahaan tersebut harus mampu mambaurkan atau menyatukan bauran promosi yang ada dengan fungsi-fungsi yang ada diperusahaan

Menurut Fandy Tjiptono (2007 : 222) Bauran Promosi terdiri dari lima alat promosi yaitu Personal Selling,Mass Sellling (Periklanan dan Hubungan Masyarakat),Promosi Penjualan,Public Relation dan Direct Marketing Secara umum berdasarkan definisi bauran promosi diatas dapat kita artikan bahwa Bauran Promosi merupakan seluruh kegiatan yang bertujuan untuk mengkomunikasikan produk perusahaan melalui iklan,promosi penjualan,Public Relation,Penjualan Personal dan Pemasaran langsung

Secara sederhana pelaksanaan bauran promosi di PT.Anugrah Parahyangan dapat digambarkan sebagai berikut

\section{Gambar 1}

Paradigma Penelitian

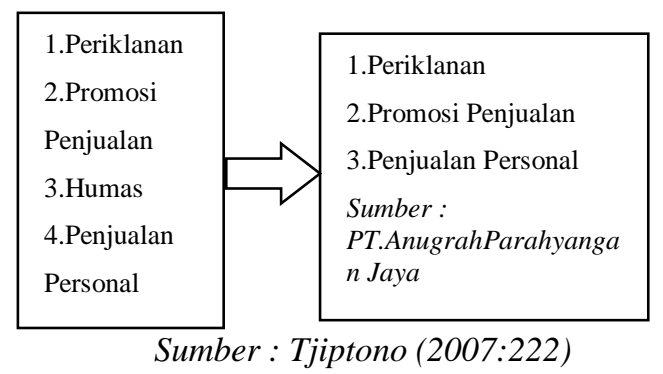

\section{Subjek/Objek Penelitian}

PT.Anugrah Parahyangan Jaya didirikan pada tahun 2004 
dengan menempati Ruko 5 A yang terletak di Jalan Surya Sumantri Bandung Telp 022-2020814 merupakan perusahaan yang bergerak dalam bidang Pembangunan, Jasa dan Perdagangan beberapa tahun kebelakang perusahaan ini akan menangani Pembangunan Pasar dan Sub Terminal Ciroyom di wilayah Ciroyom

\section{Objek Penelitian}

Menurut jenisnya, penelitian ini merupakan penelitian deskriptif. Sugiyono (2008:11) mengungkapkan bahwa "Penelitian deskriptif adalah penelitian yang dilakukan untuk mengetahui nilai variabel mandiri, baik satu variabel atau lebih (independen) tanpa membuat perbandingan, atau menghubungkan dengan variabel lain". Karena variabel yang digunakan dalam penelitian ini adalah variabel mandiri, maka penelitian ini disebut juga penelitian univariate (variabel tunggal).

\section{Operasional Variabel}

Objek penelitian yang akan diteliti dalam penelitian ini adalah bauran promosi pada PT..Anugrah Parahyangan Jaya, Bauran promosi adalah suatu ramalan khusus yang terdiri dari iklan, penjualan pribadi, promosi penjualan dan hubungan masyarakat yang dipergunakan perusahaan untuk mencapai tujuan iklan dan pemasarannya yang dilakukan oleh PT.Anugrah Parahyangan Jaya

Tabel. 2

Operasional Variabel

\begin{tabular}{|c|c|c|c|c|c|c|c|}
\hline No & Variabel & $\begin{array}{c}\text { Sub } \\
\text { Variabel } \\
\end{array}$ & Konsep Variabel & Indikator & Ukuran & Skala & $\begin{array}{l}\text { No. } \\
\text { Item }\end{array}$ \\
\hline 1 & 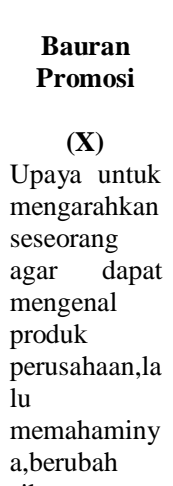 & $\begin{array}{l}\text { Advertisin } \\
\qquad \begin{array}{c}\mathbf{g} \\
\left(\mathbf{X}_{1}\right)\end{array}\end{array}$ & $\begin{array}{llr}\text { Bentuk } & \text { komunikasi tidak } \\
\text { langsung yang didasari pada } \\
\text { informasi tentang keunggulan atau } \\
\text { keuntungan } & \text { suatu produk,yang } \\
\text { disusun sedemikian rupa sehingga } \\
\text { menimbulkan rasa menyenangkan } \\
\text { yang akan mengubah pikiran } \\
\text { seseorang } & \text { untuk } & \text { melakukan } \\
\text { pembelian } & \text { Fandy } & \text { Tjiptono } \\
(\mathbf{2 0 0 7 : 2 2 6 )} & & \end{array}$ & $\begin{array}{l}\text { - Iklan Di } \\
\text { Radio. } \\
\text { - Brosur. } \\
\text { - Billboard }\end{array}$ & $\begin{array}{l}\text { - Tingkat } \\
\text { Frekuensi iklan } \\
\text { Di Radio. } \\
\text { - Kejelasan } \\
\text { informasi di } \\
\text { Brosur. } \\
\text { - Tingkat } \\
\text { Keseringan } \\
\text { melihat Iklan di } \\
\text { Billboard }\end{array}$ & $\begin{array}{l}\text { Ordin } \\
\text { al }\end{array}$ & A2 \\
\hline 2 & $\begin{array}{l}\text { S1kap,menyu } \\
\text { kai,yakin } \\
\text { akhirnya } \\
\text { membeli dan } \\
\text { selalu ingat } \\
\text { akan produk } \\
\text { tersebut } \\
\text { Fandy } \\
\text { Tjiptono } \\
(\mathbf{2 0 0 7 : 2 2 2 )} \\
\end{array}$ & $\begin{array}{c}\text { Sales } \\
\text { Promotion } \\
\left(\mathbf{X}_{2}\right)\end{array}$ & $\begin{array}{l}\text { Bentuk persuasi langsung melalui } \\
\text { penggunaan berbagai insentif } \\
\text { yang dapat diatur untuk } \\
\text { merangsang pembelian produk } \\
\text { dengan segera dan atau } \\
\text { meningkatkan jumlah barang yang } \\
\text { dibeli pelanggan. Fandy Tjiptono } \\
(\mathbf{2 0 0 7 : 2 2 9 )}\end{array}$ & $\begin{array}{l}\text { - Potongan } \\
\text { Harga/Discou } \\
n t\end{array}$ & $\begin{array}{l}\text { - } \text { Tingkat } \\
\text { Potongan Harga }\end{array}$ & & A4 \\
\hline
\end{tabular}




\begin{tabular}{|c|c|c|c|c|c|}
\hline $\mathbf{3}$ & $\begin{array}{c}\text { Personal } \\
\text { Selling } \\
\left(\mathrm{X}_{3}\right)\end{array}$ & $\begin{array}{l}\text { Komunikasi langsung } \\
\text { (tatap muka) antara penjual } \\
\text { dan calon pelanggan untuk } \\
\text { memperkenalkan suatu } \\
\text { produk kepada calon } \\
\text { pelanggan dan membentuk } \\
\text { pemahaman pelanggan } \\
\text { terhadap produk sehingga } \\
\text { mereka kemudian akan } \\
\text { mencoba membelinya } \\
\text { Fandy Tjiptono } \\
(\mathbf{2 0 0 7 : 2 2 6 )}\end{array}$ & - Pameran & $\begin{array}{l}\text { - Tingkat } \\
\text { - Pemahama } \\
\text { n Produk. } \\
\text { - Tindak } \\
\text { lanjut salles } \\
\text { (Agent) }\end{array}$ & A6 \\
\hline
\end{tabular}

Sumber; dari berbagai teori

\section{Teknik Pengumpulan Sampel}

Teknik pengumpulan data untuk mengetahui populasi, perlu terlebih dahulu dikemukakan pengertian yaitu seperti yang dikemukakan oleh Sugiyono (2008:57) bahwa : "Populasi adalah wilayah generalisasi yang terdiri atas: obyek/subyek yang mempunyai kuantitas dan karakteristik tertentu yang ditetapkan oleh peneliti untuk dipelajari dan kemudian ditarik kesimpulannya“.

Sedangkan menurut Nawawi (2001:141) : "Populasi adalah keseluruhan obyek penelitian yang dapat terdiri dari manusia, bendabenda, hewan, tumbuh-tumbuhan, gejala-gejala, nilai test atau peristiwa peristiwa sebagai sumber data yang memiliki karakteristik tertentu didalam suatu penelitian".

Sesuai dengan kedua pengertian di atas yang menjadi populasi dalam penelitian ini adalah orang yang mau membeli kios atau toko dipasar diroyom dan penulis mengambil sampel sebanyak 120 orang ini karena orang yang sudah membeli kios dan toko dipasar ciroyom waktu penulis meneliti adalah sebanyak 120 Dengan demikian teknik pengambilan sampel untuk dijadikan responden dalam penelitian ini menggunakan sampling jenuh atau sensus

\section{Teknik Pengumpulan Data}

Teknik pengumpulan data yang diperlukan dalam penelitian berupa data primer dan data sekunder.

Data primer adalah data yang diperlukan atau dikumpulkan dengan melakukan penelitian lapangan dengan cara langsung terjun ke lapangan (perusahaan). Sedangkan data sekunder adalah data yang dikumpulkan melalui penelitian kepustakaan.

Oleh karena itu teknik pengumpulan data merupakan prosedur yang sistematis dan standar untuk memperoleh data yang diperlukan. Dalam penelitian ini, penulis menggunakan Teknik Dokumentasi yaitu pengumpulan data dilakukan dengan menelaah dokumen-dokumen tentang kegiatan promosi pada PT.Anugrah Parahyangan Jaya yang terdiri dari Iklan yang dipakai oleh perusahaan, Promosi penjualan yang suka dilakukan dan penjualan pribadi yang sering perusahaan lakukan Data 
diperoleh langsung dari unit analisis (data primer) dan sumber lain yang mendukung penelitian ini (data sekunder).

\section{Rancangan Analisis Data} Menurut Patton, 1980 (dalam Lexy J. Moleong 2002:103) "Menjelaskan bahwa analisis data adalah proses mengatur urutan data, mengorganisasikanya ke dalam suatu pola, kategori, dan satuan uraian dasar".

Jika dikaji, pada dasarnya
definisi lebih
menitikberatkan pengorganisasian
data sedangkan yang ke dua lebih
menekankan maksud dan tujuan
analisis data. Dengan demikian
definisi tersebut dapat disatukan
menjadi:

"Analisis data proses mengorganisasikan dan mengurutkan data ke dalam pola,kategori dan satuan uraian dasar sehingga dapat ditemukan tema dan dapat dirumuskan hipotesis kerja seperti yang didasarkan oleh data"

Dalam menganalisis data penulis menggunakan metode perhitungan rata-rata (mean), modus, dan median didalam ilmu statistik untuk lebih lanjut dijelaskan sebagai berikut :

\section{Perhitungan Rata-rata (Mean)}

Menurut Sujana (2001:114) mendefinisikan "rata-rata hitungan atau mean merupakan bilangan yang berasal dari jumlah keseluruhan nilai bilangan dibagi dengan banyaknya bilangan". Rata-rata ini digunakan untuk melihat bagai mana suatu kumpulan data menunjukan arah pengelompokan tertentu sehingga melihat rata-rata dari kumpulan data. Rumus rata-rata yang bisa digunakan adalah :

$$
\mathrm{M}=\frac{\sum f x}{\mathrm{~N}}
$$

Keterangan :

$\mathrm{M}=$ mean (rata-rata)

$\mathrm{f} \quad=$ frekuensi

$\mathrm{x} \quad=$ masing-masing nilai bilangan

$\mathrm{N}$ = banyaknya bilangan $\sum f$

\section{Perhitungan Modus}

Menurut Sujana

(2001:115) mendefinisikan "modus adalah nilai atau data yang paling banyak muncul atau frekuensi pemunculannya paling banyak". Rumus untuk menghitung modus sebagai berikut :

$$
\mathrm{M}_{o}=L+\left[\frac{f a}{f a+f b}\right] i
$$

Keterangan :

Mo = Modus

$\mathrm{L}=$ batas bawah nyata kelas interval yang mengandung $M o$

$f a$ = frekuensi yang ada diatasnya

$f b=$ frekuensi yang ada

dibawahnya

$\mathrm{i} \quad=$ besarnya kelas interval

\section{Perhitungan Median}

Menurut Sujana

(2001:115) mendefinisikan median "sebagai nilai titik tengah yang membagi seluruh data atau bilangan menjadi dua bagian yang sama besarnya". Dalam mencari median untuk data tunggal, bilangan diurutkan terlebih dahulu mulai dari yang terkecil hingga yang terbesar. Apabila bilangannya ganjil, median terletak pada satu urutan, 
tetapi apabila jumlah bilangannya genap mediannya terletak pada dua urutan. Rumus untuk menghitung median secara rinci adalah sebagai berikut :

$$
\mathrm{M}_{d}=L+\left[\frac{1 / 2^{n-f_{c b}}}{f_{i}}\right] i
$$

Keterangan :

$M_{d}=$ median

$\mathrm{L} \quad=$ batas bawah nyata nilai yang mengandung $M_{d}$

$\mathrm{n} \quad=$ banyaknya bilangan

$f_{c b} \quad=$ angka dibawah frekuensi kumulatif dari bawah nilai yang mengandung $M_{d}$

$f i=$ frekuensi nilai yang mengandung median

\section{Hasil Penelitian}

Dalam penelitian ini, diambil sampel sejumlah 125 orang, akan tetapi jumlah sampel yang berhasil penulis kumpulkan adalah sebanyak 120 orang. Dalam metode penarikan sampel yang digunakan yaitu metode penarikan sampel jenuh, yang mana menurut Sugiyono, (2008 : 77) penarikan sampel secara jenuh adalah teknik penentuan sampel dimana semua populasi diambil seluruhnya, yaitu siapa saja yang membeli kios dan toko dipasar Ciroyom dapat digunakan sebagai sampel, Adapun yang menjadi sampel dalam penelitian ini adalah semua orang yang sudah membeli kios dan toko dipasar diroyom dan konsumen tersebut dapat menjawab seluruh pertanyaan yang diberikan oleh peneliti dilakukan melalui kuesioner. Dengan cara tersebut, dapat dipastikan bahwa jawaban responden benar-benar sesuai fakta yang di temui dan dirasakan oleh responden baik secara langsung maupun tidak langsung.

Setelah itu seluruh responden diklasifikasikan berdasarkan jenis kelamin, usia, pendidikan dan pekerjaan. Adapun perinciannya sebagai berikut .

\section{Jenis Kelamin Responden}

Berdasarkan pada klasifikasi jenis kelamin, responden digolongkan menjadi dua golongan yaitu laki-laki dan perempuan, adapun hasil yang diperoleh adalah sebagai berikut :

Tabel.3

Jenis Kelamin responden

\begin{tabular}{|c|c|c|}
\hline $\begin{array}{c}\text { Jenis Kelamin } \\
\text { Responden }\end{array}$ & $\begin{array}{c}\text { Jum } \\
\text { lah }\end{array}$ & $\begin{array}{c}\text { Persen } \\
\text { tase }\end{array}$ \\
\hline Laki-laki & 84 & $70 \%$ \\
\hline Perempuan & 36 & $30 \%$ \\
\hline Jumlah & $\mathbf{1 2 0}$ & $\mathbf{1 0 0 \%}$ \\
\hline \multicolumn{2}{|r}{ Sumber : Data Diolah }
\end{tabular}

Dari tabel 3. diatas, dapat diketahui bahwa jumlah responden laki-laki lebih banyak dibanding perempuan.hal ini dikarenakan responden yang ditemui banyak lakilaki yang memerlukan kios atau pasar di ciroyom lebih banyak sedangkan untuk perempuan hanya membantu suaminya saja Namun jumlah tersebut hanyalah kebetulan saja, karena metode penarikan sampel yang digunakan penulis adalah metode penarikan sampel jenuh. 
1. Usia Responden

Tabel 4

Usia Responden

\begin{tabular}{|c|c|c|}
\hline Usia Responden & Jumlah & Persentase \\
\hline Dibawah 20 tahun & 12 & $10 \%$ \\
\hline 20-30 tahun & 30 & $25 \%$ \\
\hline 30-40 tahun & 60 & $50 \%$ \\
\hline Diatas 40 tahun & 18 & $15 \%$ \\
\hline Jumlah & $\mathbf{1 2 0}$ & $\mathbf{1 0 0 \%}$ \\
\hline
\end{tabular}

Sumber : Data Diolah

Dari tabel 4 diatas diketahui bahwa persentase terbesar responden berada pada rentang usia antara 30 40 tahun. Hal ini disebabkan orang yang mempunyai kios dan toko di pasar Ciroyom berada pada rentang usia ini.

\section{Pendidikan Terakhir Responden}

Tabel 5

Pendidikan Terakhir Responden

\begin{tabular}{|c|c|c|}
\hline $\begin{array}{c}\text { Pendidikan Terakhir } \\
\text { Responden }\end{array}$ & $\begin{array}{c}\text { Jumla } \\
\text { h }\end{array}$ & $\begin{array}{c}\text { Persenta } \\
\text { se }\end{array}$ \\
\hline SLTA & 12 & $10 \%$ \\
\hline DIPLOMA & 78 & $65 \%$ \\
\hline S1 & 18 & $15 \%$ \\
\hline S2 & 12 & $10 \%$ \\
\hline S3 & 0 & $0 \%$ \\
\hline Jumlah & $\mathbf{1 2 0}$ & $\mathbf{1 0 0 \%}$ \\
\hline \multicolumn{3}{|c|}{ Sumber: Data Diolah }
\end{tabular}

Dari tabel 5 diatas terlihat bahwa jumlah responden terbesar berpendidikan terakhir Diploma, hal tersebut berada pada tingkat persentase $65 \%$.karena pemilik kios dan toko di pasar Ciroyom berpendidikan diploma
3. Pekerjaan Responden

Tabel 6

\begin{tabular}{|c|c|c|}
\hline $\begin{array}{c}\text { Pekerjaan } \\
\text { Responden }\end{array}$ & $\begin{array}{c}\text { Jum } \\
\text { lah }\end{array}$ & $\begin{array}{c}\text { Persen } \\
\text { tase }\end{array}$ \\
\hline Pelajar/Mahasiswa & 25 & $20.83 \%$ \\
\hline PNS/TNI/POLRI & 10 & $8.33 \%$ \\
\hline $\begin{array}{c}\text { Karyawan } \\
\text { Swasta/BUMN }\end{array}$ & 20 & $16.67 \%$ \\
\hline Guru/ Dosen & 5 & $4.17 \%$ \\
\hline Wiraswasta & 45 & $37.50 \%$ \\
\hline Lain-lain & 15 & $12.50 \%$ \\
\hline Jumlah & $\mathbf{1 2 0}$ & $\mathbf{1 0 0 \%}$ \\
\hline
\end{tabular}

Sumber : Data Diolah

Dari tabel 6 diatas terlihat bahwa responden terbesar berada pada responden yang pekerjaannya termasuk kedalam "wiraswasta". Ini menunjukkan yang mau membuka kios diroyom orang yang sudah punya usaha tetapi ingin memperluas usahanya

\section{Analisis Responden}

Tanggapan

Tanggapan responden akan di analisis,semua jawaban responden akan dibobotkan dengan mengalikan jumlah responden yang menjawab dengan nilai skala likert dari jawaban tersebut.Setelah itu nilai bobot tersebut dibandingkan dengan nilai bobot standar untuk mengetahui hasil kinerjanya. Nilai bobot standar tersebut dibagi dalam tiga rentang penilaian yaitu Sangat Setuju, Setuju, dan Tidak Setuju

Untuk mencari nilai bobot standar dapat dilakukan dengan mencari panjang rentang bobot ketiga pengklasifikasian diatas. Adapun langkahnya adalah sebagai berikut :

$$
\begin{aligned}
& \mathrm{PI}=\frac{\text { Bmaks }-\mathrm{B} \text { min }}{3} \\
& \mathrm{PI}=\frac{(3 \times 120)-(1 \times 120)}{3}
\end{aligned}
$$


$\mathrm{R}=80$

Keterangan :

$R \quad=$ Panjang Interval

Bmaks $=$ Bobot Jawaban Maksimum

Bmin = Bobot Jawaban Minimum

Kemudian pembobotan dibagi kedalam 3 tingkatan berdasarkan pengklasifikasian diatas, dimulai dari tingkatan terendah sampai kepada tingkatan tertinggi dengan panjang rentang diatas yaitu 120. adapun klasifikasi nilai bobot standar yang dihasilkan adalah sebagai berikut :

\section{Tabel 7}

\begin{tabular}{|c|c|}
\hline Nilai Bobot & Kategori \\
\hline 120-199 & $\begin{array}{l}\text { Tidak Sering/Tidak } \\
\text { menarik/Tidak jelas }\end{array}$ \\
\hline $200-279$ & $\begin{array}{l}\text { Cukup Sering/Cukup } \\
\text { menarik/Tidak jelas }\end{array}$ \\
\hline $280-360$ & $\begin{array}{c}\text { Sering/Menarik/Tida } \\
\text { k jelas }\end{array}$ \\
\hline
\end{tabular}

Dengan membandingkan nilai bobot jawaban responden dengan nilai bobot standar tersebut, maka diketahui gambaran bagaimana kinerja kebijakan dari masing-masing variabel baik itu advertising, sales promotion dan personal selling apakah tergolong baik, cukup baik, atau tidak baik. Hal ini dapat diketahui dengan melihat nilai bobot jawaban berada di golongan yang mana sesuai dengan kategori diatas.

\section{Hasil Analisis Data \\ 1 Variabel Advertising $\left(X_{1}\right)$}

Tabel 8

Variabel advertising $\left(X_{1}\right)$ Item

Pertanyaan 1

\begin{tabular}{|c|c|c|c|c|c|}
\hline Variabel & $\begin{array}{c}\text { No.i } \\
\text { tem }\end{array}$ & Skor & Jml & $\begin{array}{c}\text { Bob } \\
\text { ot }\end{array}$ \\
\hline Periklanan & 1 & 3 & 40 & $\begin{array}{c}33,3 \\
\%\end{array}$ & 120 \\
\hline & & 2 & 80 & $\begin{array}{c}66,7 \\
\%\end{array}$ & 160 \\
\hline & & 1 & 0 & $0 \%$ & 0 \\
\hline Total & & & $\mathbf{1 2 0}$ & $\begin{array}{c}\mathbf{1 0 0} \\
\mathbf{\%}\end{array}$ & $\mathbf{2 8 0}$ \\
\hline
\end{tabular}

Bagaimana Frekuensi penayangan iklan PT.Anugrah Parahyangan Jaya di Radio?

Sumber : hasil Penghitungan

Dari Tabel 8 di atas terlihat bahwa bobot kejelasan pesan iklan adalah 280 nilai tersebut berada pada rentang 280-360 atau berada pada kategori sering. Dari hasil ini dapat dikatakan bahwa indikator ini memiliki kinerja yang baik. Sehingga perusahaan sudah mampu meningkatkan kejelasan iklan sehingga konsumen dapat mendapatkan informasi dengan sangat jelas dari iklan tersebut

\section{Tabel 9}

Variabel advertising $\left(\mathbf{X}_{1}\right)$ Item

Pertanyaan 2

Bagaimana menurut Anda tentang kejelasan informasi yang dimuat di brosur?

\begin{tabular}{|c|c|c|c|c|c|}
\hline $\begin{array}{c}\text { Variab } \\
\text { el }\end{array}$ & $\begin{array}{l}\mathbf{N} \\
\text { o.i } \\
\text { te } \\
\text { m }\end{array}$ & $\begin{array}{l}\text { Sk } \\
\text { or }\end{array}$ & $\begin{array}{c}\mathbf{J} \\
\mathbf{m} \\
\mathbf{l}\end{array}$ & $\%$ & $\begin{array}{c}\text { Bo } \\
\text { bo } \\
\text { t }\end{array}$ \\
\hline $\begin{array}{c}\text { Perikla } \\
\text { nan }\end{array}$ & 2 & 3 & 38 & $\begin{array}{l}31, \\
7 \%\end{array}$ & 114 \\
\hline & & 2 & 82 & $\begin{array}{l}68, \\
3 \% \\
\end{array}$ & 164 \\
\hline & & 1 & 0 & $0 \%$ & 0 \\
\hline Total & & & $\begin{array}{c}12 \\
0\end{array}$ & $\begin{array}{c}\mathbf{1 0} \\
\mathbf{0} \\
\%\end{array}$ & 278 \\
\hline
\end{tabular}

Dari Tabel 9 terlihat bahwa bobot kesan iklan PT.Anugrah Parahyangan adalah 278, nilai 
tersebut berada pada rentang 200-279 atau berada pada kategori cukup jelas, sehingga dapat dikatakan bahwa informasi yang ada dibrosur sudah cukup jelas tetapi alangkah baiknya perusahaan meningkatkannya lagi dengan memperjelas isi brosur.

Tabel 10

Variabel advertising $\left(\mathbf{X}_{1}\right)$ Item Pertanyaan 3

Anda sering melihat iklan

PT.Anugrah Parahyangan Jaya di Billboard pada tempat yang berbeda?

\begin{tabular}{|c|c|c|c|c|c|}
\hline Variabel & $\begin{array}{c}\text { No. } \\
\text { ite } \\
\text { m }\end{array}$ & $\begin{array}{c}\text { Sko } \\
\mathbf{r}\end{array}$ & Jml & \% & $\begin{array}{c}\text { Bob } \\
\text { ot }\end{array}$ \\
\hline $\begin{array}{c}\text { Periklana } \\
\text { n }\end{array}$ & 3 & 3 & 37 & $\begin{array}{c}\% \\
\%\end{array}$ & 111 \\
\hline & & 2 & 83 & $\begin{array}{c}69 \\
\%\end{array}$ & 166 \\
\hline & & 1 & 0 & $0 \%$ & 0 \\
\hline Total & & & $\mathbf{1 2 0}$ & $\begin{array}{c}\mathbf{1 0 0} \\
\mathbf{\%}\end{array}$ & $\mathbf{2 7 7}$ \\
\hline
\end{tabular}

Sumber : hasil Penghitungan

Dari Tabel 10 di atas terlihat bahwa bobot kesenangan melihat iklan PT.Anugrah Parahyangan Jaya adalah 277 , nilai tersebut berada pada rentang 200 - 279 atau berada pada kategori cukup sering. Sehingga dapat dikatakan bahwa konsumen cukup sering melihat Billboard PT.Parahyangan Jaya, Manajemen tinggal berpikir bagaimana menaikkan kualitas iklan untuk menempatkan Billboard di tempat strategis konsumen saat melihat iklan PT.Anugrah Parahyangan Jaya menjadi lebih baik.
Tabel 11

Bobot Variabel Advertising $\left(\mathbf{X}_{1}\right)$

\begin{tabular}{|c|c|c|c|}
\hline Variabel & $\begin{array}{r}\text { Total } \\
\text { Bobot }\end{array}$ & $\%$ & Bobot \\
\hline Frekwensi Iklan & 280 & $\begin{array}{c}33,5 \\
\%\end{array}$ & Sering \\
\hline Kejelasan Brosur & 278 & $33 \%$ & Cukup Jelas \\
\hline $\begin{array}{c}\text { Banyaknya } \\
\text { Billboard }\end{array}$ & 277 & $\begin{array}{c}33,2 \\
\%\end{array}$ & $\begin{array}{l}\text { Cukup } \\
\text { sering }\end{array}$ \\
\hline Total & 835 & $\begin{array}{c}100 \\
\%\end{array}$ & \\
\hline Rata-rata & 278 & & Cukup baik \\
\hline
\end{tabular}

Dari Tabel 11 di atas dapat dilihat bahwa bobot rata-rata variabel advertising adalah sebesar 280. Ini berarti berada pada rentang 200 - 279 atau berada pada kategori cukup baik. Sehingga dapat dikatakan bahwa Periklanan PT.Anugrah Parahyangan Jaya memiliki kualitas yang cukup baik. Sehingga Perusahaan harus mampu meningkatkan kualitas agar periklanan PT.Anugrah Parahyangan Jaya menjadi lebih baik

\section{2 . Variabel Promosi Penjualan $\left(\mathbf{X}_{2}\right)$}

\section{Tabel 12}

Variabel Sales Promotion $\left(\mathbf{X}_{2}\right)$

Item pertanyaan 1

Bagaimana menurut Anda tentang potongan harga yang diberikan oleh PT.Anugrah Parahyangan Jaya?

\begin{tabular}{|c|c|c|c|c|c|}
\hline Variabel & $\begin{array}{c}\text { No } \\
\text {.ite } \\
\mathbf{m}\end{array}$ & $\begin{array}{c}\text { Sk } \\
\text { or }\end{array}$ & $\begin{array}{c}\text { Jm } \\
\mathbf{l}\end{array}$ & $\begin{array}{c}\text { \% } \\
\text { Bo } \\
\text { bot }\end{array}$ \\
\hline $\begin{array}{c}\text { Promosi } \\
\text { Penjuala } \\
\text { n }\end{array}$ & 1 & 3 & 65 & $\begin{array}{c}5 \% \\
2 \%\end{array}$ & 195 \\
\hline & & 2 & 55 & $\begin{array}{c}4 \% \\
8 \%\end{array}$ & 110 \\
\hline & & 1 & 0 & $0 \%$ & 0 \\
\hline & & & $\mathbf{1 2}$ & $\begin{array}{c}\mathbf{1 0} \\
\mathbf{0} \\
\mathbf{\%}\end{array}$ & $\mathbf{3 0 5}$ \\
\hline Tumber : hasil Penghitungan
\end{tabular}


Dari tabel 12 terlihat bahwa bobot potongan penjualan adalah 305 , nilai tersebut berada pada rentang 280-360 yang berarti termasuk kategori menarik. Dengan hasil ini dapat dikatakan bahwa potongan harga yang dilakukan oleh PT.Anugrah Parahyangan Jaya sudah menarik konsumen.

\section{Tabel 13}

Variabel Sales Promotion $\left(\mathbf{X}_{2}\right)$

Item pertanyaan 2

Bagaimana menurut Anda tentang Rate Khusus yang diberikan oleh PT.Anugrah Parahyangan Jaya?

\begin{tabular}{|c|c|c|c|c|c|}
\hline Variabel & $\begin{array}{c}\text { No.i } \\
\text { tem }\end{array}$ & $\begin{array}{c}\text { Sko } \\
\text { r }\end{array}$ & Jml & \% & $\begin{array}{c}\text { Bob } \\
\text { ot }\end{array}$ \\
\hline $\begin{array}{c}\text { Promosi } \\
\text { Penjualan }\end{array}$ & 2 & 3 & 78 & $65 \%$ & 234 \\
\hline & & 2 & 42 & $35 \%$ & 84 \\
\hline & & 1 & 0 & $0 \%$ & 0 \\
\hline & & & $\mathbf{1 2 0}$ & $\begin{array}{c}\mathbf{1 0 0} \\
\text { \% }\end{array}$ & $\mathbf{3 1 8}$ \\
\hline
\end{tabular}

Dari Tabel 13 di atas terlihat bahwa bobot mengundang pembeli adalah 318, nilai tersebut berada pada rentang 280 - 360 atau berada pada kategori manarik. Berarti dalam hal ini rate khusus sangat di sambut baik oleh konsumen , sehingga perusahaan harus mempunyai program tentang penjualan dengan rate khusus PT.Anugrah Parahyangan Jaya agar dipertahankan agar konsumen tidak beralih ke perusahaan lain.
Tabel 14

Bobot Variabel Sales Promotion

(X)

\begin{tabular}{|c|c|c|c|}
\hline Variabel & $\begin{array}{c}\text { Total } \\
\text { Bobot }\end{array}$ & $\mathbf{\%}$ & Bobot \\
\hline Potongan harga & 305 & $50 \%$ & Menarik \\
\hline Rate Khusus & 318 & $50 \%$ & Menarik \\
\hline Total & $\mathbf{6 2 3}$ & $\mathbf{1 0 0 \%}$ & $\mathbf{0}$ \\
\hline Rata-rata & 311.5 & & Baik \\
\hline
\end{tabular}

Sumber : hasil Penghitungan

Dari Tabel 14 terlihat bahwa bobot rata-rata variabel sales promotion adalah sebesar 311,5 , nilai tersebut berada pada rentang 280 360 atau berada pada kategori baik. Sehingga dapat dikatakan secara umum bahwa variabel sales promotion patut di pertahankan. Namun Perusahaan masih bisa meningkatkan kinerja agar hasil yang diperoleh menjadi lebih baik.

\section{Variabel Penjualan Pribadi ( $\left.\mathbf{X}_{3}\right)$}

Variabel Penjualan Pribadi $\left(\mathrm{X}_{3}\right)$ ini terdiri dari 2 item pertanyaan, yaitu :

\section{Tabel 15}

Variabel Penjualan Pribadi $\left(\mathbf{X}_{3}\right)$

Item Pertanyaan 1

Sales/ Agen kami menguasai / memahami product knowledge ketika mempresentasikan produk PT.Anugrah Parahyangan Jaya dan ketika menjawab pertanyaan Anda?

\begin{tabular}{|c|c|c|c|c|c|}
\hline Variabel & $\begin{array}{l}\text { No.i } \\
\text { tem }\end{array}$ & Skor & Jml & $\%$ & $\begin{array}{c}\text { Bobo } \\
t\end{array}$ \\
\hline $\begin{array}{c}\text { Penjualan } \\
\text { Pribadi }\end{array}$ & 1 & 3 & 76 & $\begin{array}{c}63,3 \\
\%\end{array}$ & 228 \\
\hline & & 2 & 44 & $\begin{array}{c}36,7 \\
\%\end{array}$ & 88 \\
\hline & & 1 & 0 & $0 \%$ & 0 \\
\hline Total & & & 120 & $\begin{array}{c}100 \\
\%\end{array}$ & 316 \\
\hline
\end{tabular}

Sumber : hasil Penghitungan 
Dari Tabel 15 di atas terlihat bahwa bobot pengetahuan tentang agen adalah 316 , nilai tersebut berada pada rentang 280 - 360 atau berada pada kategori memahami. Hal ini berarti pengetahuan produk PT.Anugrah Parahyangan Jaya sudah dipahami oleh konsumen.

Tabel 16

Variabel Penjualan Pribadi $\left(\mathbf{X}_{3}\right)$

Item Pertanyaan 2

Bagaimana kinerja Sales /agen kami dalam menindaklanjuti permintaan Anda?

\begin{tabular}{|c|c|c|c|c|c|}
\hline Variabel & $\begin{array}{c}\text { No.i } \\
\text { tem }\end{array}$ & Skor & Jml & \% & $\begin{array}{c}\text { Bobo } \\
\text { t }\end{array}$ \\
\hline $\begin{array}{c}\text { Penjualan } \\
\text { Pribadi }\end{array}$ & 2 & 3 & 84 & $70 \%$ & 252 \\
\hline & & 2 & 36 & $30 \%$ & 72 \\
\hline & & 1 & 0 & $0 \%$ & 0 \\
\hline Total & & & $\mathbf{1 2 0}$ & $\begin{array}{c}\mathbf{1 0 0} \\
\text { \% }\end{array}$ & $\mathbf{3 2 4}$ \\
\hline
\end{tabular}

Sumber : hasil Penghitungan

Dari Tabel 16 di atas terlihat bahwa bobot tindak lanjut agen PT.Anugrah Parahyangan Jaya adalah 324, nilai tersebut berada pada rentang 280 - 360 atau berada pada kategori baik. Hal ini berarti tindak lanjut agen PT.Anugrah Parahyangan Jaya sudah masuk kategori baik.

\section{Tabel 17}

Bobot Variabel Penjualan

Pribadi ( $\left.\mathrm{X}_{3}\right)$

\begin{tabular}{|c|c|c|c|}
\hline $\begin{array}{c}\text { Variabel } \\
\text { Bobot }\end{array}$ & $\%$ & Bobot \\
\hline $\begin{array}{c}\text { Pemahaman } \\
\text { Product } \\
\text { knowledge }\end{array}$ & 316 & $49 \%$ & Baik \\
\hline Kinerja Sales & 324 & $51 \%$ & Baik \\
\hline Total & $\mathbf{6 4 0}$ & $\mathbf{1 0 0 \%}$ & $\mathbf{0}$ \\
\hline Rata-rata & 320 & & Baik \\
\hline
\end{tabular}

Dari tabel 17 di atas terlihat bahwa bobot rata-rata variabel Penjualan Pribadi adalah 320, nilai tersebut berada pada rentang 280 360 atau masuk kategori baik. Sehingga dapat dikatakan variabel Penjualan Pribadi memiliki kinerja yang baik. Maka pihak PT.Anugrah Parahyangan Jaya harus mempertahankannya

\section{Tabel 18}

Bobot Bauran Promosi (X)

\begin{tabular}{|c|c|c|c|}
\hline Variabel & $\begin{array}{c}\text { Total } \\
\text { Bobot }\end{array}$ & $\boldsymbol{\%}$ & Bobot \\
\hline Periklanan & 278 & $18 \%$ & Cukup baik \\
\hline $\begin{array}{c}\text { Promosi } \\
\text { Penjualan }\end{array}$ & 311.5 & $21 \%$ & Baik \\
\hline $\begin{array}{c}\text { Penjualan } \\
\text { pribadi }\end{array}$ & 320 & $20 \%$ & Baik \\
\hline Total & $\mathbf{9 0 9 , 5}$ & $\mathbf{1 0 0 \%}$ & $\mathbf{0}$ \\
\hline Rata-rata & 303 & & Baik \\
\hline
\end{tabular}

Sumber : hasil Penghitungan

Dari tabel 18 di atas terlihat bahwa bobot rata-rata variabel bauran promosi adalah 303, nilai tersebut berada pada rentang 280 - 360 atau masuk kategori baik. Sehingga dapat dikatakan secara umum variabel bauran promosi memiliki kinerja yang baik. Maka pihak PT.Anugrah Parahyangan Jaya harus meningkatkan kinerja dalam hal bauran promosi, sehingga dapat memperoleh nilai lebih baik.

\section{Pembahasan}

1. Validitas Variabel Bauran Promosi

Tabel 19

Validitas Bauran Promosi

\begin{tabular}{|c|c|c|c|c|}
\hline Item & $\mathbf{r}_{\text {s-hitung }}$ & $\mathbf{n}$ & $\mathbf{r}_{\text {s-tabel }}$ & Keterangan \\
\hline $\mathrm{X} 1.1$ & 0.981 & 120 & 0.176 & VALID \\
\hline $\mathrm{X} 1.2$ & 0.994 & 120 & 0.176 & VALID \\
\hline $\mathrm{X} 1.3$ & 0.987 & 120 & 0.176 & VALID \\
\hline $\mathrm{X} 2.1$ & 1.000 & 120 & 0.176 & VALID \\
\hline $\mathrm{X} 3.1$ & 0.966 & 120 & 0.176 & VALID \\
\hline $\mathrm{X} 3.2$ & 0.963 & 120 & 0.176 & VALID \\
\hline
\end{tabular}


Bila dilihat dari tabel diatas maka semua pernyataan yang diajukan penulis semuanya valid jadi semuanya bisa diikutsertakan ke penelitian selanjutnya

\section{Reabilitas Variabel Bauran Promosi}

Tabel 20

Reabilitas Bauran Promosi

\begin{tabular}{|c|c|c|c|c|}
\hline Item & $\mathbf{r}_{\text {s-hitung }}$ & $\mathbf{n}$ & $\mathbf{r}_{\text {s-tabel }}$ & Keterangan \\
\hline $\mathrm{X} 1$ & 0.993 & 120 & 0.176 & Reliabel \\
\hline $\mathrm{X} 2$ & 1.000 & 120 & 0.176 & Reliabel \\
\hline $\mathrm{X} 3$ & 0.925 & 120 & 0.176 & Reliabel \\
\hline \multicolumn{5}{c}{ Sumber : hasil Penghitungan }
\end{tabular}

Dari tabel diatas maka semua pernyataan yang diajukan penulis semuanya reliabel artinya pengukuran untuk pernyataan ini konsisten

Setelah dihubungkan antara analisis data, gambaran umum responden dan hasil tanggapan responden pelaksanaan bauran promosi di PT.Anugrah Parahyangan Jaya dapat diuraikan sebagai berikut :

1. Bobot iklan (Advertising) yang dilakukan oleh perusahaan berada pada rentang 200-279 atau cukup baik, perusahaan harus dapat meningkatkannya lagi menjadi baik dengan menambah frekwensi penayangan iklan dan penambahan Billboard di tempat-tempat yang strategis supaya konsumen lebih mengenal PT.Anugrah Parahyangan Jaya sehingga kios dan toko yang dipasarkan lebih laku dan laba perusahaan akan naik ini sesuai dengan pendapat Fandy Tjiptono (2007:226) yang menyatakan iklan adalah
"Bentuk komunikasi tidak langsung yang didasari pada informasi tentang keunggulan atau keuntungan suatu produk, yang disusun sedemikian rupa sehingga menimbulkan rasa menyenangkan yang akan mengubah pikiran seseorang untuk melakukan pembelian

2. Bobot rata-rata promosi penjualan ada pada rentang 280-360 atau berada pada kategori baik ini berarti promosi yang dilakukan perusahaan sudah sesuai harapan tinggal perusahaan mempertahankannya agar konsumen loyal terhadap perusahaan kita dan dapat menarik pelanggan baru,mempengaruhi pelanggannya untuk mencoba produk baru,mendorong pelanggan membeli lebih banyak dan menyerang aktivitas pomosi pesaing Fandy Tjiptono (2007:229)

1. Bobot rata-rata penjualan pribadi ada pada rentang 295,5 atau ada dalam kategori baik ini menunjukkan sales PT.Anugrah Parahyangan Jaya sudah melakukan hal yang diinginkan oleh perusahaan, sales perusahaan dapat mengamati reaksi pelanggan dan menyesuaikan pendekatannya,usaha yang sia-sia dapat diminimalkan,pelanggan yang berminat bisa langsung membeli dan penjual dapat membina hubungan jangka panjang dengan pelanggannya

2. Bobot rata-rata bauran promosi PT.Anugrah 
Parahyangan Jaya sebesar 293 berada pada rentang $280-360$ atau masuk pada kategori baik jadi penulis dapat menyimpulkan bahwa secara umum bauran promosi yang dilakukan PT.Anugrah Parahyangan Jaya sudah memiliki kinerja yang baik namun PT.Anugrah Parahyangan Jaya bisa mencoba dua variabel bauran promosi yang lain supaya volume penjualan perusahaan tidak naik turun

\section{Kendala-kendala dalam pelaksanaan Bauran Promosi dalam memasarkan produk kios dan toko Pasar Ciroyom di PT.Anugrah Parahiyangan Jaya}

1. Faktor-faktor yang menjadi penghambat pelaksanaan Bauran Promosi di PT.Anugrah Parahyangan Jaya yaitu :

a. Bila dilihat dari bobot pernyataan Brosur yang disebarkan oleh perusahaan berada dalam kategori cukup dipahami ini manandakan biasanya hanya dibaca dalam waktu singkat dan terbatas dalam penyajiannya tidak mendetail sedangkan konsumen ingin mengetahui produk dengan detail

b. Bobot Pemasangan Billboard yang dilakukan oleh perusahaan berada dalam kategori cukup ini manandakan Billboard mempunyai kelemahan yaitu memiliki tingkat kreativitas yang terbatas sedangkan konsumen perlu lebih rinci pengetahuan tentang produk misalnya tentang harga yang ditawarkan

\section{Pemecahan masalah Pelaksanaan Bauran Promosi di PT.Anugrah Parahyangan Jaya}

a. Isi brosur disesuaikan dengan kebutuhan perusahaan misalnya menonjolkan harga yang murah,fasilitas yang lengkap,tempat yang strategis sehingga konsumen merasa tertarik untuk membeli

b. Billboard yang dipasang dijalan harus memiliki isi yang singkat tapi menarik sehingga masyarakat luas terekpos untuk memandangnya

\section{Kesimpulan}

Pelaksanaan Bauran Promosi di PT.Anugrah Parahyangan Jaya meliputi :

1. Iklan di radio, pemasangan Billboard di tempat-tempat yang strategis, Brosur-brosur yang disebarkan ditempat-tempat keramaian dengan iklan ini diharapkan konsumen lebih mengenal PT.Anugrah Parahyangan Jaya sehingga perusahaan dapat menuai hasil dari tujuan diadakannya iklan

2. Promosi penjualan yang dilakukan di PT.Anugrah Parahyangan Jaya menggunakan potongan harga berupa discount time apabila konsumen membeli kios atau toko pada waktu tertentu dan ini terbukti efektif untuk merangsang penjualan dalam waktu yang pendek dan dalam jangka panjang perusahaan dapat menarik pelanggan baru 
3. Penjualan personal pada PT.Anugrah Parahyangan Jaya dengan cara komunikasi langsung antara Sales Promotion Girl dengan konsumen, biasanya PT.Anugrah Parahyangan Jaya mengikuti pameran dagang property yang diselenggarakan oleh Event Orgazer sehingga terjadi kontak langsung antara $S P G$ PT.Anugrah Parahyangan Jaya dengan konsumen

Yang menjadi Faktor-Faktor Penghambat Pelaksanaan Bauran Promosi di PT.Anugrah Parahyangan Jaya dapat penulis simpulkan :

Brosur yang disebarkan oleh perusahaan hanya dibaca dalam waktu singkat dan terbatas dalam penyajiannya tidak mendetail sedangkan konsumen ingin mengetahui produk dengan detail

Pemasangan Billboard yang dilakukan oleh perusahaan memiliki tingkat kreativitas yang terbatas sedangkan konsumen perlu lebih rinci pengetahuan tentang produk misalnya tentang harga yang ditawarkan

\section{Saran}

Ada beberapa saran yang dapat diajukan disini yaitu antara lain:

1. Perusahaan hendaknya menambah Billboard di tempattempat yang strategis supaya konsumen lebih mengenal PT.Anugrah Parahyangan Jaya sehingga kios dan toko yang dipasarkan lebih laku dan laba perusahaan akan naik

2. Potongan harga yang dilakukan oleh perusahaan hendaknya disesuaikan dengan permintaan konsumen supaya bobotnya seimbang dengan rate khusus

3. Pemahaman produk Sales PT.Anugrah Parahyangan Jaya hendaknya ditingkatkan lagi agar konsumen betul-betul tertarik terhadap produk PT.Anugrah Parahyangan Jaya

4. Periklanan PT.Anugrah Parahyangan Jaya hendaknya ditambah dengan media lain supaya penjualan perusahaan naik

\section{DAFTAR PUSTAKA}

Basu Swastha dan

Irawan.2002.Manajemen

Pemasaran Modern.Edisi

Kedua,Cetakan

ketujuh,Yogyakarta : Penerbit

Liberty Offset.

Bilson Simamora.2007.Manajemen

Pemasaran, Jakarta : Salemba

Empat

Buchori Alma.2002.Manajemen

Pemasaran dan Pemasaran

Jasa, Bandung : Alfabeta.

Fandy Tjiptono.2007. Strategi

Pemasaran, Yogyakarta :

Penerbit Andi Offset.

Harun Al-Rasyid. 2006.Dasar-dasar

Statistika Terapan.

Pascasarjana-UNPAD, Jakarta 
VOL. 2 NO. 2 JANUARI - JUNI 2018 e-ISSN: 2621-5306

VOL. III NO. 1 JANUARI - JUNI 2018 p-ISSN: 2541-5255

Kotler, Philip, 2002.Manajemen Pemasaran. Edisi Millenium Bahasa Indonesia, New Jersey : Prentice Hall International.

Kotler ,Amstrong 2004.Dasar-dasar Pemasaran,

Edisi

Kesembilan, Jilid 2 Jakarta : PT.Indeks.

Kotler,Susanto.2001.Manajemen

Pemasaran, Jakarta : Salemba

Lawrence,Gluek 1990.Business

Policy And Strategi

Manajemen,Mc Graw Hill

Lexy J.Maleong.2002.Metode

Analisis Data,

Masri Singarimbun, Sofyan

Effendi.1995.Metode

Penelitian Survey.Edisi

Revisi,Jakarta:LP3ES

Moh. Nazir. 2003.Metode

Penelitian.Cetakan ketiga,

Jakarta : Ghalia Indonesia.

Mursid. 2009. Manajemen

Pemasaran, Edisi I Jakarta :

Bumi Aksara

Murti Sumarni.2002.Manajemen

Pemasaran Bank, Yogyakarta :

PT.Liberty

Rachmawati.2007.Metode Penelitian

Deskriptif. Bandung : Alfabeta
Sugiyono, 2008. Metode Penelitian Administrasi, Bandung : Alfabeta

Suharsimi Arikunto.2006.Prosedur Penelitian Suatu Pendekatan Praktek. Jakarta:Rineka Cipta.

Sumarti. 2003,Metode Penelitian Bisnis, Yogyakarta : Andi Offset

Sumarti, Soepriharto. 2003. Manajemen Umum Suat Pengantar,Yogyakarta : BPFE

Tatang Kusmayadi. 2009. Jurnal Manajemen Pemasaran, Yogyakarta : Universitas Gajah Mada 